\title{
O FUTEBOL / FUTSAL E AS POLÍTICAS PÚBLICAS DAS CIDADES DO ESTADO DO PARANÁ ${ }^{1}$
}

\author{
João Paulo Melleiro Malagutti \\ Universidade Federal de Goiás, Jataí, Goiás, Brasil \\ Edson Hirata \\ Universidade Tecnológica Federal do Paraná, Campo Mourão, Paraná, Brasil \\ Fernando Augusto Starepravo \\ Universidade Estadual de Maringá, Maringá, Paraná, Brasil
}

\begin{abstract}
Resumo
O futebol é considerado uma paixão nacional, sendo um dos objetos sociais mais complexos de análise. Desde sua chegada ao país, o futebol foi traçado cuidadosamente até se consolidar como uma identidade nacional, tornando-se o "país do futebol". A partir desse pressuposto o objetivo deste artigo é identificar a presença de ações e projetos públicos de futebol/futsal oferecidos pelas estruturas administrativas responsáveis pelo esporte nos municípios do estado do Paraná e enunciar possíveis explicações para os números encontrados. Como resultado, encontramos uma superioridade do número de projetos esportivos do futebol/futsal frente a outras modalidades, justificado pela procura dos cidadãos por projetos relacionados com o futebol, mediante a uma cultura da prática do futebol já imposta.
\end{abstract}

Palavras-chave: Políticas Públicas; Esporte; Futebol; Futsal.

\section{Introdução e problematização}

O futebol representa um dos maiores fenômenos sociais no Brasil e sua história e prática são repassadas de geração a geração, originando até a ideologia de que o Brasil é o "País do Futebol". Ao decorrer de seu percurso histórico, o futebol, assim como as variadas práticas esportivas, foi utilizado como ferramenta política em muitos governos, além de sua representação de entretenimento para seus praticantes.

Como exemplos do uso político do futebol se destacam alguns períodos históricos, como a era Vargas e sua política centralizadora do Estado Novo, o uso alienante do futebol durante a Ditadura Militar, até dias atuais, com a mídia e grandes conglomerados controlando sua organização e prática (GASTALDO, 2009; GUTERMAN, 2009; HELAL; SOARES; LOVISOLO, 2001).

Além dos períodos ditatoriais mencionados anteriormente, a ligação entre o Futebol e o Brasil, possui fortes laços durante outros contextos políticos brasileiros. Em outros períodos

\footnotetext{
${ }^{1} \mathrm{O}$ artigo apresenta dados referentes ao Projeto de Pesquisa intitulado "Análise dos Agentes Públicos do Sistema Nacional de Esporte", contemplado com fomento do Edital 091/2013 do Ministério do Esporte e do Conselho Nacional de Desenvolvimento Científico e Tecnológico - CNPq. 
históricos podemos observar a forte influência do Estado, assim como da iniciativa privada e de ex-jogadores de futebol, diretamente ligados à relação Futebol-Estado (MEZZADRI et al., 2011).

Essa lógica do uso político do futebol, assim como do esporte em geral, está presente na maioria dos segmentos políticos brasileiros, desde governo federal, estadual e municipal (SIGOLI; DE ROSE JR., 2004; ARENA; BÖHME, 2000; HALLAL et al., 2009).

A partir desse contexto político, entendendo o esporte como um objeto de política pública (MEZZADRI, 2011), origina-se a ideia central do estudo, e se apoiando aos dados obtidos durante a realização de um projeto de pesquisa ${ }^{2}$, buscou-se identificar a presença do futebol nas ações realizadas pelos departamentos ou entidades legais voltadas ao esporte nos municípios do estado do Paraná.

O presente trabalho apresenta-se como uma pesquisa descritiva direta e explicativa. As pesquisas diretas têm como objetivo a descrição de determinada população ou fenômeno e/ou estabelecer uma relação entre as variáveis. Já as pesquisas explicativas têm como preocupação identificar os fatores que determinam ou que contribuem para a ocorrência de fenômenos (GIL, 2008).

Foram utilizados como apoio à discussão teórica, dados coletados a partir de entrevistas semiestruturadas com 77 dirigentes públicos dos órgãos responsáveis pelo desenvolvimento do esporte nos municípios realizadas durante a coleta de dados do Projeto de Pesquisa contemplado pelo Conselho Nacional de Desenvolvimento Científico e Tecnológico (CNPq) supracitado. As entrevistas buscaram analisar a realidade esportiva dos municípios visitados, identificando as principais características e modo de ação dos agentes. O projeto de pesquisa foi aprovado, Parecer $n^{\circ}$ 548.551, pelo Comitê Permanente de Ética em Pesquisa com Seres Humanos (COPEP) da Universidade Estadual de Maringá (UEM).

É importante salientar o caminho metodológico utilizado para a obtenção dos dados com os entrevistados do referido Projeto de Pesquisa. Foram visitados 77 municípios paranaenses, classificados, segundo o IBGE (2010) como municípios de Pequeno Porte I, Pequeno Porte II, Médio Porte e Grande Porte ${ }^{3}$.

Os municípios de Pequeno Porte I possuem uma maior representatividade em relação a realidade dos municípios do estado, sendo que dos 399 municípios que o estado do Paraná contém, 312 são considerados de Pequeno Porte I. Nossa mostra evidencia esta realidade, sendo composta por 60 municípios de Pequeno Porte I, 11 municípios de Pequeno Porte II, três municípios de Médio Porte e também três municípios de Grande Porte.

Dentre os sujeitos entrevistados estão secretários e diretores municipais de esporte, secretários de órgãos que administram o esporte municipal e professores que respondem pela gestão do esporte nos municípios. Após a coleta de dados, as entrevistas foram transcritas e analisadas por meio da Análise de Conteúdo de Bardin (2006), e utilizados os dados como apoio teórico para as discussões. Os dados apresentam em recortes das falas dos gestores, que são identificados por meio de números, pois foi garantido o anonimato aos mesmos para a realização das entrevistas.

\section{O futebol e o processo de criação da identidade nacional}

A história do futebol em seu extenso desenvolvimento, do início de sua prática, sua chegada ao Brasil e seu desenvolvimento até dias atuais, já foi e ainda é amplamente descrita

\footnotetext{
${ }^{2}$ Projeto de Pesquisa realizado pelo Grupo de Pesquisa em Políticas Públicas de Esporte e Lazer (GEPPOL) da Universidade Estadual de Maringá (UEM).

${ }^{3}$ Classificação de acordo com o IBGE (2010): Municípios de Pequeno Porte I - Até 20 mil habitantes; Pequeno Porte II - De 20.001 a 50 mil habitantes; Médio Porte - De 50.001 a 100 mil habitantes; e Grande Porte - De 100.001 a 900 mil habitantes.
} 
e debatida em muitos trabalhos acadêmicos (FRANZINI, 2009; SANTOS, 2009; LUCENA, 2001). Em seus estudos, Franzini (2009) e Lucena (2001) apresentam o processo de chegada do futebol, relatando as primeiras partidas recreativas entre funcionários aduaneiros de Belém do Pará até a cidade de Rio Grande no Rio Grande do Sul.

Já Santos (2009) descreve um dos períodos de maior tensão entre os atletas do futebol nos primórdios de sua prática, as disputas entre a elite praticante e a crescente participação de adeptos oriundos de classes populares, além da tensão principal, a questão dos praticantes negros no futebol ${ }^{4}$.

Com o crescimento do interesse e da prática do futebol no território brasileiro, sobretudo nas camadas populares, o seu uso inicial como fator de distinção social não se consolidou, diferentemente do caso do turfe e dos Sportsman $^{5}$ da época, demonstrando a apropriação de uma prática esportiva por meio de uma classe social. (LUCENA, 2001).

Além das classes sociais, o futebol foi um dos responsáveis por uma importante reviravolta no cenário político. No período histórico conhecido como Estado Novo, um período do primeiro governo de Getúlio Vargas, o futebol, assim como todos os esportes, foram regulamentados ${ }^{6}$ com suas próprias confederações e associações, onde todas as entidades respondiam a uma organização maior, o Conselho Nacional de Desportos (MANHÃES, 2002).

Por que somente naquele período ocorreu a normatização do esporte e do futebol no Brasil? Qual a relevância do futebol para sociedade naquele momento? [...] Inicialmente, supõe-se que a legislação auxiliou na construção da identidade nacional, pois a bandeira do Estado Novo era a de consolidar a base nacionalista. Possivelmente, nesse caso, a identidade social, representada pelo Estado, tornou-se bastante presente nas configurações dos indivíduos, e o futebol cumpriu seu papel, de maneira direta ou indireta, no processo de fortalecimento do Estado (MEZZADRI et al., 2011, p. 408).

Ou seja, o futebol era praticado em todas suas manifestações, seja recreativo ou profissional e atendia a todas as parcelas da sociedade, do patrão ao empregado, do dominante ao dominado. Diferentemente do que Fry (1982) relata, identificando a apropriação de algumas práticas das classes dominadas pelas classes dominantes, como as danças e a culinária, a criação de uma identidade nacional, o futebol, era uma maneira de unir todas as camadas da sociedade, na tentativa de criar um autorreconhecimento próprio de uma só uma nação, o país do futebol.

Acentuo que, diferentemente do samba, das religiões afro-brasileiras e da culinária "étnica" (feijoada, vatapá etc.), o futebol não é uma produção dos grupos dominados, embora tendo, uma penetração mais difusa no Brasil, mesmo em seus primórdios. Se é, obviamente, importando da Inglaterra, e se constitui de um lado, em prática de lazer de jovens de camadas dominantes, foi tão rapidamente apropriado por outros segmentos da sociedade que podemos considerá-lo como tendo múltiplas entradas (GUEDES, 2009, p. 455).

\footnotetext{
4 Um dos casos mais emblemáticos desse período trata-se do atleta do Fluminense Football Club, Carlos Alberto. Mulato, o jogador passava pó de arroz em sua face para escapar dos gritos das torcidas adversárias, originando assim um dos apelidos do clube carioca. Santos (1981, p. 16) destaca: "Corre pela última vez ao espelho e tome nova camada de pó-de-arroz! Retira cuidadosamente a gorra de meia - o cabelo duro assentado até o cocuruto[...] [...] Carlos Alberto está quase feliz. Ninguém o xingou até aqui. Será que escapa desta vez? De repente o grito da geral trespassa-lhe o coração: "Pó-de-arroz". Campo do Fluminense, Rio, 1912".

5 Segundo Lucena (2001), os Sportsman eram os membros da elite carioca que frequentavam os clubes de turfe da cidade do Rio de Janeiro durante o Brasil Império.

${ }^{6}$ Decreto-Lei 3.199/41 (BRASIL, 1941)
} 
A busca por estabelecer uma identidade nacional, além de criar uma unidade no país, teria o intuito de criar, de acordo com Bauman (2005), uma identidade superior às demais, como de gênero e classe, por exemplo. De fato, a criação de uma identidade nacional por meio do futebol conseguiu se estabelecer e mantém-se firme até dias atuais, com a união dos brasileiros em torno de um evento como a Copa do Mundo de Futebol da FIFA, com a criação de certos rituais, como a grande união popular em dias de jogos (DaMATTA, 1997).

De acordo com a ideologia de Durkheim (1989), a Copa do Mundo pode ser entendida para os brasileiros, como um período de recriação periódica do sentimento de pertencimento comum. Essa lógica está presente em algumas sociedades modernas, com a utilização de datas com celebrações coletivas, sendo assim Guedes (2008), utilizando o conceito de ideologia de Durkheim (1989), sugere que a Copa do Mundo para os brasileiros representa um importante período para os brasileiros, aflorando o sentimento de pertencimento para os brasileiros, em um período de união dos brasileiros em torno de uma competição esportiva. Segundo o mesmo autor, podemos utilizar como exemplo para demonstrar o sentimento de pertencimento, a partir de datas representativas de importantes conquistas cívicas, como o exemplo do feriado 4 de julho para os americanos.

O esforço de tomar o futebol como manifestação da cultura brasileira, por conseguinte, como fator de identidade nacional resultou de uma construção elaborada ao longo do tempo - uma vez que o gosto pelo futebol não é inerente ao brasileiro - e acompanhou o processo de popularização do esporte (ANTUNES, 2004, p. 27).

Portanto, pode-se destacar a importância do futebol para o povo brasileiro, como um processo desenvolvido há muito tempo e que ainda poderá se perdurar por mais alguns anos se tal lógica se mantiver. Ao longo dos anos o Brasil foi e é considerado o país do futebol, mesmo sendo questionado devido aos maus resultados e à gestão confusa da Confederação Brasileira de Futebol (CBF) (REVISTA PLACAR, 2015; WASSERMAN, 2013).

Tal cenário pode nos causar certa inquietude, frente à prática dos demais esportes, como o basquete, handebol e voleibol? No próximo tópico discutiremos como se apresenta o futebol frente às demais modalidades esportivas, com o enfoque principal nas modalidades coletivas tradicionais, futebol/futsal ${ }^{7}$, basquete, handebol e voleibol.

\section{Massificação do futebol frente a outras modalidades}

Como visto anteriormente, o futebol é o principal esporte do Brasil e dos brasileiros, oriundo de um processo de construção de uma identidade nacional em torno de um esporte. Considerado como uma paixão nacional, o futebol representa o esporte de maior investimento profissionalmente, de maior visibilidade na mídia televisiva e de números de atletas assalariados (CALIL, 2012). Tal fato pode ser justificado pela ideologia posta de que o Brasil é país do futebol.

De acordo com Santos et al. (1997), em uma análise superficial das práticas esportivas dos brasileiros, os esportes com bola, movimentação e participação coletiva representam a preferência esportiva dos brasileiros, com o futebol concentrado praticamente toda a atenção da população. Ainda segundo o mesmo autor, o basquete desperta o interesse na população, principalmente no estado de São Paulo, já o voleibol teve uma crescente graças aos recentes

\footnotetext{
${ }^{7}$ Neste estudo abordaremos o futebol e futsal como uma modalidade, pois o futsal representa uma modificação do futebol e ainda é regido pela mesma entidade, a Fédération Internationale de Football Association (FIFA).
} 
resultados alcançados nas competições internacionais e o handebol apresenta-se muito praticado nas escolas, porém, com competições oficiais inexpressivas e o pouco apoio por parte dos patrocinadores e da mídia esportiva nacional, sua prática limita-se as escolas e aos clubes esportivos.

A partir do relato acima podemos identificar a paixão e a dedicação destinada ao futebol pelos brasileiros, frente a outros esportes. Embora o futebol não se apresente como o principal esporte nas escolas, devido a uma estrutura compactada das quadras e estruturas esportivas, o futsal corresponde ao objetivo no futebol, sendo um dos esportes mais praticados nas escolas. Os outros esportes praticados nas escolas, como o caso do handebol, não tem continuidade fora do âmbito escolar e tampouco no esporte profissional, não obtendo assim grandes destaques.

Santos et al. (1997) identificam alguns fatores que levam outros esportes a ficarem atrás do futebol nas pesquisas de popularidades, como a cobertura marginal da mídia e de comentaristas esportivos, esportes amplamente praticados em outros países são extremamente elitizados em nosso país e as poucas ações tomadas para a reversão desse quadro. Podemos citar ainda, de acordo com Melo (2010, p. 113), a busca de esportes e atividades físicas fora do ambiente tumultuado da cidade pelos membros da elite.

Em instante aproximado, na medida em que a gestação mais clara de uma indústria do entretenimento traz em seu bojo o crescimento de alternativas de uma maior mistura social, inclusive como estratégias de distinção também melhor se sistematizam algumas práticas mais ligadas a um estilo de vida burguês, ou melhor, à nova conformação das elites, estabelecendo pontes entre os diferentes estratos das altas camadas. Nesse cenário, destacam-se o críquete, o croquete, o golfe, o tênis e o iatismo.

Corroborando com esse fato, a Deloitte, uma empresa de consultoria e auditoria, lançou em 2011 a pesquisa "Muito Além do Futebol - Estudo sobre esportes no Brasil". Com o objetivo de realizar um panorama geral sobre interesse e a prática de esportes pelos brasileiros, a pesquisa foi realizada com mais de 700 pessoas, por meio de questionário on-line. $\mathrm{O}$ estudo apresentou respostas de todas as regiões do Brasil, de variadas faixas etárias e classes sociais.

Como dados obtidos nesta pesquisa, podemos destacar o cenário esportivo no Brasil, representado pela Figura 1, destacando os esportes e atividades físicas mais praticados no Brasil.

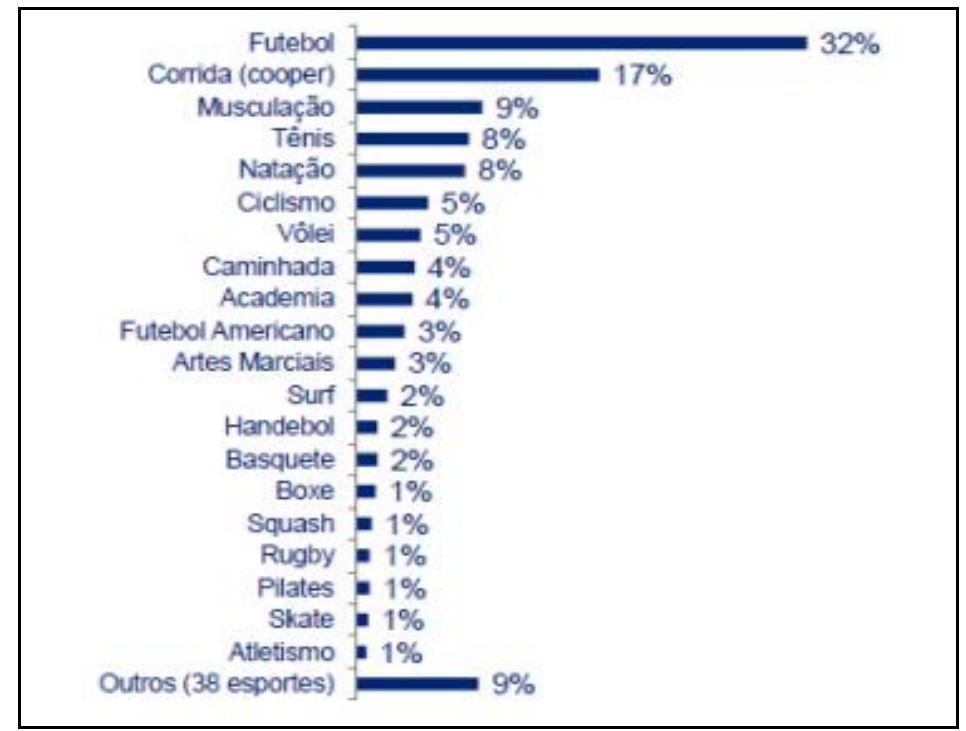


FIGURA 1 - Esportes e atividades físicas mais praticadas no Brasil. Fonte: (DELOITTE. 2011, p. 2)

Como podemos observar, há o amplo domínio do futebol frente às outras modalidades esportivas (basquete, voleibol e handebol). Em outro cenário, com informações obtidas na mesma pesquisa, a prática do futebol crescerá mais nos próximos anos, apresentando números superiores em relação às outras modalidades coletivas correlacionadas (DELOITTE, 2011).

Portanto, temos um cenário posto, onde a prática do futebol é massiva frente a outras modalidades esportivas. O ensino do futebol pode ocorrer em variados ambientes, como clubes esportivos, nas escolas durante o turno ou contraturno escolar, além das escolinhas e projetos desenvolvidos pelas entidades responsáveis pelo esporte nos centros esportivos dos municípios (ARENA; BÖHME, 2000).

Podemos ainda utilizar as Leis esportivas que vigoram atualmente no Brasil, para demonstrar a força do Futebol perante às outras modalidades esportivas no Brasil, com a utilização de nomes de grandes atletas da modalidade em leis que regem todas as organizações esportivas no país. Em 1993 foi decretada a Lei 8.672/93 (Lei Zico), posteriormente sendo substituída pelo decreto de Lei 9.615/98, popularmente conhecida como Lei Pelé (MEZZADRI et al., 2011; STAREPRAVO, 2011).

Durante a realização da pesquisa foi observado um alto número de escolinhas e projetos de iniciação no futebol encontrados frente a outras modalidades esportivas nas cidades pesquisadas durante a realização do Projeto de Pesquisa: Análise dos Agentes Públicos do Sistema Nacional de Esporte.

\section{Resultados e discussões}

É um importante ressaltar que a pesquisa se baseou nas políticas públicas e projetos desenvolvidos pelas estruturas administrativas esportivas presentes nos municípios. Segundo Rua (2009, p. 19) a "política pública geralmente envolve mais do que uma decisão e requer diversas ações estrategicamente selecionadas para implementar as decisões tomadas". De acordo com a Constituição Federal do Brasil (BRASIL, 1988) é dever do poder público, por meio das políticas públicas, assegurar o desenvolvimento urbano, visando ao desenvolvimento social e ao bem-estar da população, destacando assim a importância em se elaborar políticas públicas de esporte e lazer nos municípios.

Como primeiro resultado, destacamos os projetos esportivos encontrados nas cidades visitadas. Utilizamos como base para a apresentação dos dados, as respostas de duas perguntas presente no roteiro de entrevista com os gestores: a) Quais são as principais ações, programas e projetos de esporte desta Secretaria/Departamento? Existe algum tipo de financiamento ou apoio externo? b) O que é priorizado/objetivado com as políticas públicas de esporte e lazer?

De acordo com os relatos dos agentes entrevistados foi elaborado um quadro demonstrativo apresentando as modalidades esportivas presentes nos municípios visitados (QUADRO 1).

\begin{tabular}{|c|c|}
\hline PROJETOS & QUANTIDADE \\
\hline FUTSAL & $\mathbf{4 8}$ \\
\hline FUTEBOL & $\mathbf{4 3}$ \\
\hline Vôlei & $\mathbf{2 7}$ \\
\hline Handebol & $\mathbf{1 7}$ \\
\hline Atletismo & 12 \\
\hline Ginástica & 11 \\
\hline Xadrez & 9 \\
\hline
\end{tabular}




\begin{tabular}{|c|c|}
\hline Basquete & 8 \\
\hline Futebol suíço & 8 \\
\hline Jogo de Cartas & 7 \\
\hline Taekwondo & 6 \\
\hline Capoeira & 5 \\
\hline Judô & 5 \\
\hline Dança & 4 \\
\hline Tênis de mesa & 4 \\
\hline Bocha & 3 \\
\hline Karatê & 3 \\
\hline Sinuca & 3 \\
\hline Badminton & 2 \\
\hline Motocross & 2 \\
\hline Outros Projetos & 86 \\
\hline TOTAL & 313 \\
\hline
\end{tabular}

QUADRO 1 - Projetos esportivos desenvolvidos pelas entidades públicas municipais. (FONTE: Os Autores, 2015).

Obs.: O item "Outros Projetos” apresenta números elevados, pois é composta por variados projetos que abordam alguns esportes ou projetos ligados à qualidade de vida. Tais dados foram agrupados para facilitar a apresentação do quadro.

A partir dos números apresentados no Quadro 1, identificamos a presença superior de projetos esportivos ligados ao futebol e futsal frente a outras modalidades esportivas, destacando as quatro principais modalidades futebol/futsal, basquete, voleibol e handebol.

A partir deste exposto, como passo seguinte, identificamos (FIGURA 2) as cidades paranaenses que apresentam projetos esportivos ligados ao futebol e futsal, diferenciando as cidades conforme a classificação utilizada na metodologia no Projeto.

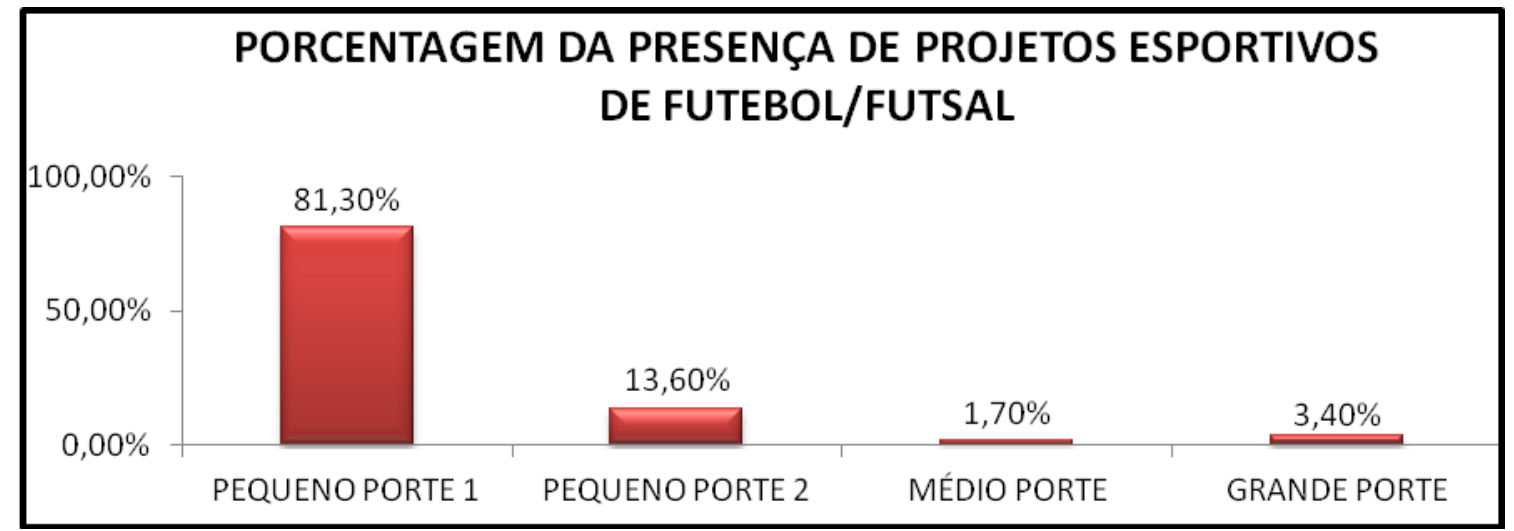

FIGURA 2 - Projetos Esportivos de Futebol/Futsal nas cidades analisadas.

(FONTE: Os Autores, 2015).

Destaca-se a diferenciação entre o número total de projetos envolvendo o futebol e o futsal, totalizando o montante de 91 projetos (Quadro 1 - soma do montante do futebol com o futsal) e o número total de 59 municípios (Figura 2) que ofertam o futebol ou futsal em suas localidades, uma vez que os municípios podem oferecer apenas uma das modalidades ou as duas simultaneamente, causando assim essa diferenciação. Ainda podemos destacar, analisando os dados conforme a Figura 3, a presença de projetos e ações voltadas somente ao futebol/futsal. 


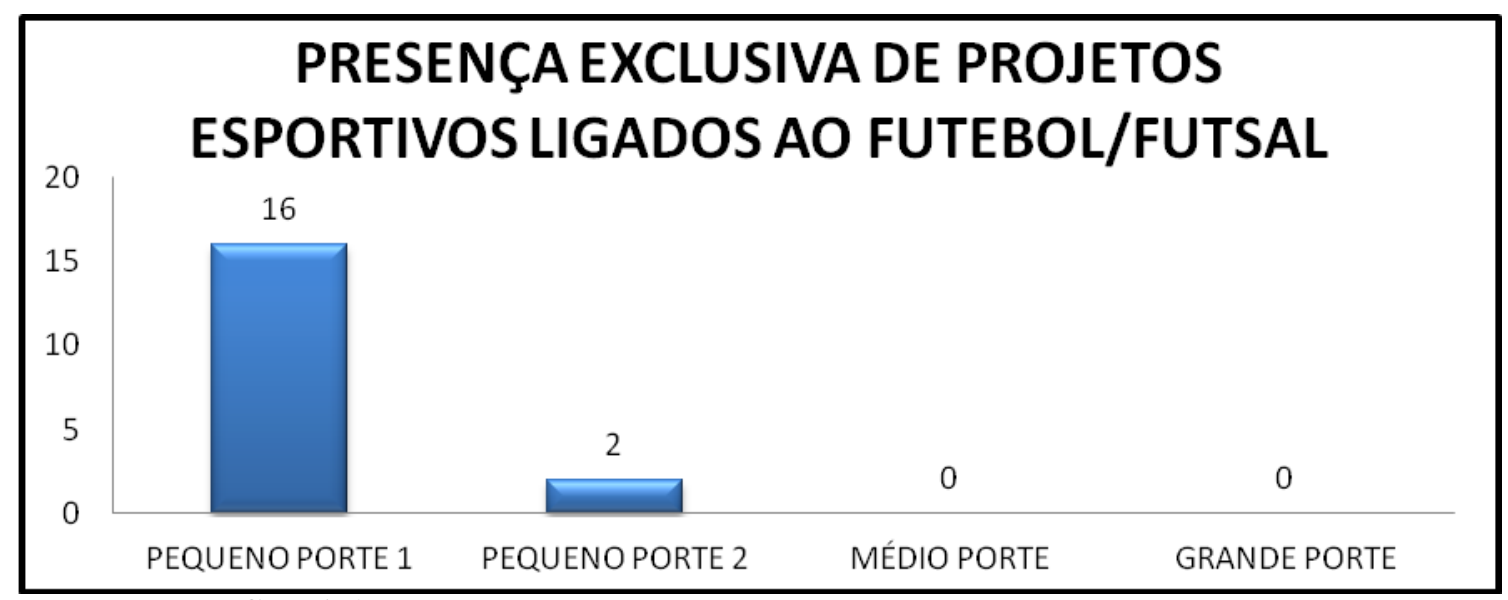

FIGURA 3 - Cidades que apresentam apenas projetos ligados ao futebol/futsal.

(FONTE: Os Autores, 2015).

Podemos observar na Figura 3 que a oferta pública de projetos e ações ligadas somente ao futebol/futsal é predominante nas cidades de pequeno porte 1, e também em algumas cidades de Pequeno Porte 2. É importante destacar ainda que em nenhuma cidade considerada como "Médio Porte" e "Grande Porte", apresenta o futebol como projeto esportivo exclusivo, podendo estar relacionado ao fato de uma maior procura por outros esportes, mediante ao maior número de habitantes das cidades. Como exemplo dessa predominância de projetos de futebol em algumas cidades paranaenses, podemos utilizar a fala do Gestor 29 (2015).

Nós começamos a desenvolver o esporte, só que nós mexemos com dois esportes aqui na Ventania. O futebol de salão e o futebol de campo. Nós temos no primeiro semestre o Futebol de Campo e no segundo semestre o Futebol de Salão.

Ou seja, para o Gestor 29, o desenvolvimento do esporte no seu município limita-se apenas ao Futebol e Futsal, realizados em diferentes épocas do ano, deixando de se desenvolver atividades ligadas a outros esportes. Ainda nessa lógica, o Gestor 67 (2015) descreve a situação do esporte em seu município, remetendo novamente a questão da prioridade do futebol.

A prioridade aqui é o futebol. Aqui sempre, desde quando eu entrei, o futebol era abandonado, não tinha. Então nós priorizamos o quê? $\mathrm{O}$ futebol, então hoje tem mais de 100 alunos que praticam o futebol, e é o ano inteiro com competição, [...] hoje a política pública aqui é voltada especialmente pra o futebol (GESTOR 67, 2015).

Identifica-se na passagem do Gestor 67, a generalização do esporte por meio da oferta do futebol aos munícipes. Outro ponto de destaque trata-se da utilização pontual do futebol e frente a um cenário abandonado da oferta do esporte. Miranda e Vieira (2002) verificaram em seu estudo que as políticas de esporte representavam prioritariamente uma administração baseada na gestão e organização de eventos pontuais e não em uma ligação lógica de ações que demonstrassem uma disposição estratégica definida.

Ou seja, ao se desenvolver o futebol como uma prioridade nas ações públicas, o gestor demonstra uma solução pontual para a falta de esporte na cidade, mas que não atende a oferta de mais variedades para os munícipes, como um planejamento anual de esportes. Podemos ainda identificar a lógica do uso político do futebol, ofertando uma prática esportiva comu- 
mente aceita pela sociedade, em detrimento de um conjunto de ações de variadas políticas públicas de esporte possíveis de serem implantadas nos municípios.

Dito de outra maneira, como se produz a demanda dos "produtos esportivos", como as pessoas passam a ter o "gosto" pelo esporte e justamente por um determinado esporte mais do que por outro, enquanto prática ou enquanto espetáculo? Mais precisamente, segundo que princípios os agentes escolhem entre as diferentes práticas ou consumos esportivos que Ihes são oferecidos como possibilidade em um dado momento? (BOURDIEU, 1983, p. 137).

Assim esse ponto de vista de Bourdieu (1983) corrobora com a situação que pode ser observada a partir de algumas falas relatadas pelos gestores entrevistados, como exemplo do Gestor 28 (2015): “[...] lá no interior não adianta você tentar fazer outra coisa que não seja futebol de salão, suíço ou campo, não adianta". Ainda na lógica da monocultura esportiva ligada ao futebol, o Gestor 34 (2015) descreve uma situação comum em determinada região: "Na nossa região aqui, 70\% dos nossos municípios pensam em futebol".

Em alguns casos, há a intenção dos gestores em inserir novos esportes, mas os mesmos relataram algumas dificuldades em inserir novos projetos esportivos nas cidades, como a recusa da população por outros esportes, fato que pode ser justificado por a ideologia imposta pela cultura do futebol, e a dificuldade em se encontrar profissionais especializados em outros esportes.

Como eu disse pra você, aqui ficou conhecido como a cidade do futebol e futsal. Tem duas modalidades, mas eu queria abranger mais modalidades, conseguir agregar mais modalidades, ter profissional capacitado para isso, conseguir atuar nessa questão de recreação e lazer também (GESTOR 3, 2015).

A Secretaria deve visar todos os tipos de esportes, não só futebol e futsal, mas procurar saber em conjunto com a população, o que eles querem. Eu fiz isso ano passado e votaram em futebol e futsal (GESTOR 50, 2015).

A dificuldade em programar outros esportes a partir da recusa ou a preferência de um esporte pelos cidadãos pode ser justificada de acordo com as palavras de Rua (2009, p. 7): "Uma preferência é a alternativa de solução para um problema que mais beneficia um determinado ator. Assim, dependendo da sua posição, os atores podem ter preferências muito diversas uns dos outros quanto à melhor solução para um problema político".

Podemos observar por meio dos relatos mencionados acima, a presença de um grande número de projetos voltados ao Futebol/Futsal, evidenciando algumas lógicas políticas e culturais pré-estabelecidas. Evidenciando DaMatta (1982), podemos destacar a utilização do futebol, por parte dos governantes, mediante a justificativa de criação de uma união popular e a totalização do país em torno do esporte.

\section{Conclusão}

O futebol é o esporte mais praticado pelo povo brasileiro. Desde sua chegada ao Brasil, o esporte rapidamente conquistou os brasileiros, desde a elite até as classes populares, encontrando assim um meio social para o seu desenvolvimento, criando assim uma paixão popular e uma identidade nacional, o país do futebol.

Tal paixão e apelo pelo futebol originaram um descompasso frente a outras modalidades esportivas, como o basquete, voleibol e handebol. O processo de elitização de alguns es- 
portes, a cobertura midiática marginal e uma cultura escolar fortemente ligada ao futsal e futebol, são alguns dos fatores que justificam a presença do futebol como principal esporte do país.

O Estado brasileiro foi fundamental para o estabelecimento do futebol como o principal esporte nacional, mediante a utilização de algumas medidas. O processo de promoção do futebol como um fator de identidade nacional, a utilização de nomes de importantes jogadores da modalidade nas leis que regem a organização do esporte brasileiro como um todo e o fortalecimento da prática do futebol nas ambientes comuns dos brasileiros, por meio das ações políticas, em projetos municipais, são algumas das ações orquestradas pelo Estado para o fortalecimento do Futebol mediante a outras modalidades esportivas.

Mediante a tal realidade, o futebol/futsal destaca-se como o principal esporte ofertado por programas e ações das entidades legais responsáveis pelo esporte nos municípios pesquisados, justificado, de acordo com as falas dos gestores, pela facilidade da aplicação do futebol mediante a procura da população pelo futebol. Podemos também, destacar a utilização da identidade nacional criada a partir da premissa de que o futebol/futsal é o principal esporte do país, exemplificado pela fala do Gestor 50 (2015): “[...] só porque estamos no país do futebol".

\title{
SOCCER / FUTSAL AND PUBLIC POLICIES OF CITIES IN THE STATE OF PARANÁ
}

\begin{abstract}
Football is considered a national passion, one of the most complex social objects of analysis. Since its arrival in the country, football has been carefully drawn up to consolidate as a national identity, making it the "country of soccer." From that assumption it originated this paper aims, which is to identify the presence of actions and public projects of soccer/futsal offered by the administrative structures responsible for sport in the municipalities and formulate possible explanations for the numbers found. As a result we find a superiority in the number of soccer/futsal projects against other modalities, justified by the demand from citizens for projects related to soccer, by a culture of football practice already imposed.
\end{abstract}

Keywords: Public Policy; Sport; Soccer; Futsal.

\section{EL FÚTBOL/ FUTSAL Y LAS POLÍTICAS PÚBLICAS DE LAS CIUDADES EN EL ESTADO DE PARANÁ}

\begin{abstract}
Resumen
El fútbol es considerado una pasión nacional, uno de los más complejos de los objetos sociales de análisis. Desde su llegada al país, el fútbol ha sido elaborado cuidadosamente hasta consolidarse como una identidad nacional, tornándose el "país del fútbol". A partir de ese presupuesto el objetivo de este artículo es identificar la presencia de acciones y proyectos públicos de fútbol/ futsal ofrecidos por las estructuras administrativas responsables por el deporte en los municipios del Estado de Paraná y enunciar posibles explicaciones para los números encontrados. Como resultado, encontramos una superioridad del número de proyectos deportivos del fútbol/ futsal frente a otras modalidades, justificado por la demanda de los ciudadanos por proyectos relacionados con el fútbol, por una cultura de la práctica ya impuesta.
\end{abstract}


Palabras clave: Políticas Públicas; Deporte; Fútbol; Futsal.

\section{Referências}

ANTUNES, F. M. R. F. Com o brasileiro, não há quem possa!: futebol e identidade nacional em José Lins do Rego, Mário Filho e Nelson Rodrigues. São Paulo: Editora UNESP, 2004.

ARENA, S. S.; BÖHME, M. T. S. Programas de iniciação e especialização esportiva na grande São Paulo. Revista Paulista Educação Física, São Paulo, 14(2):184-95, jul./dez. 2000.

BARDIN, L. Análise de Conteúdo. Lisboa: Edições 70, 2006.

BAUMAN, Z. Identidade: entrevista a Benedetto Vecchi/Zygmunt Bauman; tradução, Carlos Alberto Medeiros. - Rio de Janeiro: Jorge Zahar Ed., 2005.

BOURDIEU, P. Questões de sociologia. Rio de Janeiro: Marco Zero. 1983.

BRASIL. Constituição da República Federativa do Brasil de 1988, de 05 de outubro de 1988. Brasília, 1988.

CALIL, L. Triste realidade: no Brasil, $82 \%$ dos jogadores de futebol recebem até dois salários mínimos. Jornal Extra. Publicado em: 23 set. 2012. Disponível em:< http://extra.globo.com/esporte/triste-realidade-no-brasil-82-dos-jogadores-de-futebolrecebem-ate-dois-salarios-minimos-6168754.html>. Acesso em: 08 nov. 2015.

DaMATTA, R. Canaviais, malandros e heróis: para uma sociologia do dilema brasileiro. Rio de Janeiro: Zahar, 1997.

DELOITTE. Rugby e artes marciais são os esportes apontados como os de maior crescimento futuro no Brasil. Deloitte Touche Tohmatsu, 2011.

DURKHEIM, É. As formas elementares da vida religiosa. São Paulo: Paulinas, 1989.

FRANZINI, F. A futura paixão nacional: chega o futebol. In: DEL PRIORE, Mary; MELO, Victor Andrade (Org.). História do esporte no Brasil: do Império aos dias atuais. São Paulo: Editora UNESP, 2009.

FRY, P. Para inglês ver: Identidade e política na cultura brasileira. Rio de Janeiro, Zahar, 1982.

GASTALDO, É. “O país do futebol” mediatizado: mídia e Copa do Mundo no Brasil. Sociologias, Porto Alegre, ano 11, n 22, p. 352-369, jul/dez. 2009,

GIL, A. C. Métodos e técnicas de pesquisa social. 6. ed. São Paulo: Atlas, 2008.

GUEDES, S. L. Futebol e identidade nacional: reflexões sobre o Brasil. In: DEL PRIORE, Mary; MELO, Victor Andrade (Org.). História do esporte no Brasil: do Império aos dias atuais. São Paulo: Editora UNESP, 2009. 
GUTERMAN, M. O futebol explica o Brasil: Uma história da maior expressão popular do país. São Paulo: Contexto, 2009.

HALLAL, P. C.; REIS, R. S.; HINO, A. A. F.; SANTOS, M. S.; GRANDE, D.; KREMPEL, M. C.; CARVALHO, Y. M.; CRUZ, D. K. A.; MALTA, D. C. Avaliação de programas comunitários de promoção da atividade física: o caso de Curitiba, Paraná. Revista Brasileira de Atividade Física \& Saúde, vol. 14(2): 104-114, 2009.

HELAL, R.; SOARES, A. J.; LOVISOLO, Hugo. Mídia, raça e idolatria: a invenção do país do futebol. Rio de Janeiro: Mauad, 2001.

IBGE. Instituto Brasileiro de Geografia e Estatística. Pesquisa Nacional por Amostra de Domicílios. Síntese dos Indicadores de 2009. Rio de Janeiro: IBGE, 2010.

LUCENA, R. de F. O esporte na cidade: aspectos do esforço civilizador brasileiro. Campinas, SP: Autores Associados, CBCE, 2001.

MANHÃES, L. E. Políticas de esportes no Brasil. 2. ed. Rio de Janeiro: Paz e Terra, 2002.

MELO, V. A. de. Apontamentos para uma história comparada do esporte: um modelo heurístico. Revista brasileira de Educação Física e Esporte, São Paulo, v.24, n.1, p.107-20, jan./mar. 2010.

MEZZADRI, F. M. O Campo esportivo no Estado do Paraná: a inserção dos clubes e as políticas públicas para o Esporte. In: XXVIII Congresso Internacional da Associação Latino Americana de Sociologia. Anais do XXVIII Congresso Internacional da Associação Latino - Americana de Sociologia, 2011.

MEZZADRI, F. M.; PRESTES, S. E. de C.; CAPRARO, A. M.; CAVICHIOLLI, F. Re.; MARCHI JÚNIOR, W. As interferências do Estado brasileiro no futebol e o estatuto de defesa do torcedor. Revista brasileira de Educação Física e Esporte, São Paulo, v.25, n.3, p.407-16, jul./set. 2011.

MIRANDA, M. de; VIEIRA, J. J. As políticas públicas esportivas do Rio Grande do Norte no ano de 2001. In: V Simpósio Mineiro de Ciências do Esporte. Anais do V Simpósio Mineiro de Ciências do Esporte. Universidade Federal de Viçosa. Minas Gerais, 2002.

REVISTA PLACAR. Em 2015, o Brasil ainda é o País do Futebol? Placar, 13 mar. 2015. Disponível em:<http://placar.abril.com.br/materia/em-2015-o-brasil-ainda-e-o-pais-dofutebol/>. Acesso em: 09 dez. 2015.

RUA, M. das G. Políticas Públicas. Florianópolis: Departamento de Ciências da Administração/UFSC; Brasília: CAPES: UAB, 2009.

SANTOS, R. P. dos. Tensões na consolidação do futebol nacional. In: DEL PRIORE, Mary; MELO, Victor Andrade (Org.). História do esporte no Brasil: do Império aos dias atuais. São Paulo: Editora UNESP, 2009.

SANTOS, J. R. dos. História política do futebol brasileiro. São Paulo: Brasiliense, 1981. 
SANTOS, A. M.; GIMENEZ, L. C.; REBOUÇAS, C.; SCHMITT, S.; RENNÓ, T. Esportes no Brasil: Situação Atual e Propostas para o Desenvolvimento. Banco Nacional de Desenvolvimento Econômico e Social. 1997.

SIGOLI, M. A.; DE R. J., D. A história do uso político do esporte. Revista Brasileira de Ciências e Movimento, vol. 12(2): 111-119. 2004.

STAREPRAVO, F. A. Políticas públicas de esporte e lazer no Brasil: aproximações, intersecções, rupturas e distanciamentos entre os subcampos político/burocrático e científico/acadêmico. Tese (Doutorado) - Universidade Federal do Paraná. Curitiba: 2011.

WASSERMANN, R. O Brasil é o país do futebol? British Broadcasting Corporation (BBC), $\quad 12$ jun. 2013.2 Disponível em:< http://www.bbc.com/portuguese/noticias/2013/06/130611_brasil_pais_do_futebol_rw>. Acesso em 09 dez. 2015.

Recebido em: 21/12/2015

Revisado em: 27/01/2016

Aprovado em: 22/02/2016

Endereço para correspondência:

joaopaulomalagutti89@hotmail.com

João Paulo Melleiro Malagutti

Universidade Federal de Goiás

R. Riachuelo, 1530

Setor Samuel Graham

Jataí - GO, 75804-020 